\title{
Effective oral combination metronomic chemotherapy with low toxicity for the management of castration-resistant prostate cancer
}

\author{
ÅSA JELLVERT ${ }^{1}$, INGELA FRANCK LISSBRANT $^{1}$, MALIHA EDGREN $^{2}$, \\ ELISABETH ÖVFERHOLM ${ }^{1}$, KARIN BRAIDE $^{1}$, ANN-MARIE EKELUND OLVENMARK ${ }^{1}$, \\ JON KINDBLOM $^{1}$, PER ALBERTSSON ${ }^{1}$ and BO LENNERNÄS ${ }^{1}$ \\ ${ }^{1}$ Department of Oncology, Sahlgrenska University Hospital, S-413 45 Gothenburg; \\ ${ }^{2}$ Onkologkliniken, Borås, Sweden
}

Received December 17, 2010; Accepted March 25, 2011

DOI: 10.3892/etm.2011.272

\begin{abstract}
Prostate cancer (PC) was previously believed to be a chemoresistant disease. In recent years taxane-based chemotherapy has been shown to prolong survival in patients with castration-resistant prostate cancer (CRPC). It remains to be shown, however, which type of chemotherapy provides the most beneficial effect with the least amount of side effects. Seventeen patients with chemonaive CRPC were enrolled in a pilot study evaluating an orally administered chemo-hormonal treatment regimen using a weekly sequential combination called KEES; consisting of ketoconazole in combination with cyclophosphamide or etoposide in combination with estramustine administered on alternate weeks. Prednisone was administered throughout the treatment period. Prostate-specific antigen (PSA) response and acute and chronic toxicities were evaluated. Seventeen patients with CRPC were treated; eleven patients demonstrated a median reduction in PSA of $87 \%$ (range 26-99\%). Ten (59\%) patients responded with a decrease in PSA $>50 \%$. Thrombocytopenia and anaemia were the most common side effects. One study fatality was reported, however, it was unclear whether this was treatment related. In conclusion, KEES may be a promising option for patients with CRPC, resulting in a clear reduction in PSA with limited toxicity. Further clinical evaluation of this metronomic chemohormonal combination is underway.
\end{abstract}

\section{Introduction}

Prostate cancer (PC) is a common and extremely variable disease (1). A major challenge of PC management is the large

Correspondence to: Dr Ingela Franck Lissbrant, Department of Oncology, Sahlgrenska University Hospital, S-413 45 Gothenburg, Sweden

E-mail: ingela.franck-lissbrant@vgregion.se

Key words: prostate cancer, castration-resistant, hormone-refractory, metronomic, chemotherapy, angiogenesis number of patients, approximately $40 \%$, who relapse after radical treatment with surgery or radiation therapy. Standard therapy for these patients is castration leading to a temporary decrease in tumor growth. Unfortunately, this effect is transient, and tumor growth ultimately resumes (in a median of 18-24 months) during a hormone-independent phase, i.e. castration-resistant PC (CRPC), eventually resulting in death due to widespread disease (1). Until recently, few treatment options have been available for these patients.

For many years, PC was believed to be a chemoresistant disease (2,3). Clinical trials with mitoxantrone in the late 90's showed only palliative effects in patients with CRPC (4). In 2004, two large randomized phase III trials [the Southwest Oncology Group (SWOG) 99-16 and the Tax 327 studies] showed that docetaxel-based therapy not only improves quality of life and decreases pain but also prolongs survival in patients with CRPC $(5,6)$. Thus, for the first time, chemotherapy was considered a treatment option for patients with CRPC, and taxane-based therapy was considered to be the gold standard. However, the drawbacks of treatment with docetaxel are that the effect on survival is slight (2-3 months), and the duration of the effect is limited to a 6-month period. Furthermore, it causes several major side effects such as neutropenia, neuropathy and fatigue (7).

Patients with CRPC include a large heterogeneous group of patients ranging from asymtomatic patients where the only sign of progression is a rising prostate-specific antigen (PSA) to patients with symptomatic metastases $(7,8)$. Furthermore, these patients are often elderly with a high degree of comorbidity. The timing and best strategy for treating these different groups of CRPC patients are not clear, but there is an obvious need for clinical trials to test different chemotherapy regimens at different stages of the disease so that the optimum therapy with the most convenient routes of administration and least amount of side effects can be defined (3).

In recent years, significant advances have been made in our understanding of the tumor biology of CRPC where both tumor cells as well as the surrounding stroma appear to play a pivotal role in tumor progression (8). Theoretically, this means that the use of a combination therapy where both tumor and 
stromal cells are targeted may confer a synergistic antitumor effect. There is a vast source of both preclinical and clinical data supporting this concept (8). Therefore, in the present study we investigated whether a combination of secondary hormonal manipulation and chemotherapy, administered metronomically, has an effect on patients with CRPC.

Metronomic chemotherapy is a regimen where low doses of chemotherapy are administered on a frequent or continuous schedule with no extended interruptions (9-11). Preclinical studies have shown that, even though the total dose of chemotherapy is lower, the tumor-inhibiting properties are just as beneficial and in some cases even better than conventionally administered chemotherapy administered at a maximumtolerated dose (MTD) $(10,11)$. The main course of action for metronomic chemotherapy is thought to be by attacking tumor stroma through its anti-angiogenic properties thereby interrupting oxygen and the nutrient supply in tumors $(10,11)$. In patients with lung, breast and ovarian cancer who stopped responding to MTD-based therapy, therapeutic effects were noted when chemotherapy was administered daily or weekly (12-14). Furthermore, maintenance therapy in childhood tumors such as leukemia is very similar to metronomic chemotherapy and has been used for years (13).

Several phase II trials with combination chemotherapy administered in a metronomic way in patients with CRPC have shown beneficial therapeutic effects (15-18). One of the most promising regimens consists of ketoconazole in combination with doxorubicin alternating with vinblastine in combination with estramustine (KA/VE) $(15,17)$. In a phase II trial with 45 patients an 8-week treatment cycle produced the most satisfactory response rates observed to date in this patient population: PSA reductions of $>50 \%$ in $31(69 \%)$ patients and $>80 \%$ in $26(58 \%)$ patients, and a median overall survival of 18.1 months; i.e. PSA responses, palliative and survival effects compared favorably and sometimes even better than early docetaxel studies $(15,17)$. The drawback, however, was toxicity. It was concluded that more tolerable regimens should be a high priority prior to moving to phase III trials.

Based on these findings, we developed a metronomic peroral chemo-hormonal treatment schedule for patients with CRPC consisting of ketoconazole in combination with cyclophosphamide or etoposide in combination with estramustine administered on alternate weeks (KEES) throughout the entire treatment period. Prednisone was administered the entire period to counteract potential adrenal insufficiency secondary to ketoconazole. All of these drugs have previously been used in PC, and much attention has been focused on possible positive and negative interactions and toxicity when choosing dose levels.

The aim of this pilot study was to study the effect (reduction in serum PSA) and toxicity of the KEES protocol in 17 patients with CRPC.

\section{Patients and methods}

Patients. Between 2003 and 2005, 17 patients with CRPC were enrolled in this study at the Oncology Department, Sahlgrenska Hospital, Gothenburg and the Department of Urology, Uddevalla Hospital, Uddevalla, Sweden. No randomization was performed. The enrolled patients were those who personally asked for further treatment once they developed CRPC. Treatment was designed to be administered in an outpatient setting. The median age of the patients was 60 years (range 40-75). All patients had histopathologically confirmed PC and had previously been treated with medical or surgical castration for a median time of 46 months (range 6-108) prior to the study. The medical castration included androgen deprivation, estrogen, anti-androgen monotherapy or combined androgen blockade (CAB). All patients had previously been treated with $\mathrm{CAB}$ for at least one period and all but five patients had experienced the effect of a therapeutic anti-androgen withdrawal. Six patients had received previous first-line treatment for CRPC. All patients except one were screened with bone scintigraphy. The clinical characteristics of the patients are presented in detail in Table I.

Chemotherapy planning. Each course of peroral chemotherapy lasted for 6 consecutive weeks, with a 2-week rest between each course. Five agents were included in the KEES schedule and administered as follows: cyclophosphamide (Sendoxan ${ }^{\circledR}$ ) (50 mg twice daily) in combination with ketaconazole (200 mg three times daily) were administered for seven consecutive days during weeks 1, 3 and 5. During weeks 2, 4 and 6, patients received seven consecutive days of etoposide (50 mg twice daily) in combination with estramustine (140 mg twice daily). One patient received idarubicin (5 mg daily 4 days a week) instead of cyclophosphamide because of hypersensitivity. A 2-week rest followed each 6-week course. Prednisone (10 mg daily) was administered throughout the entire treatment period to couteract potential ketoconazoleinduced adrenal complications. At the start of treatment each patient was provided with a KEES schedule to aid in the correct administration of the various drugs.

Treatment planning. The baseline visit was conducted at the outpatient clinic at Sahlgrenska University Hospital and included a physical examination and blood tests: serum PSA (prostate specific antigen), Hemoglobin ( $\mathrm{Hb})$, white blood cell count (WBC), platelets, aspartate transaminase (AST), alanine transaminase (ALT), bilirubin and creatinine. Blood tests were repeated monthly and at the start of each new course. Monthly contact with the doctor was maintained through telephone or when needed by a clinical appointment. A clinical staff nurse could easily be reached and was available to the patients. Prior to the start of each new chemotherapy course, a physical examination was performed.

PSA levels were used to follow the effect of chemotherapy and were recorded at least every 8 weeks. Patients with bone metastases that demonstrated a serum-PSA reduction by at least 50\% after 2-3 courses were evaluated with the intention to administer strontium (Sr-89) when no contraindications were found. For patients with a PSA reduction of $<50 \%$, a third course was administered. Patients with no bone metastases received a third KEES course, when there were no contraindications and good tolerability was noted. No patient received more than 3 courses of chemotherapy. PSA response was determined by using the baseline value and the nadir value after 2-3 courses (i.e. 4-6 months) of chemotherapy.

The choice of the consolidating regimen depended on patient symptoms and tumor burden. Those with soft tissue 
Table I. Clinical characteristics of the patients.

\begin{tabular}{|c|c|c|c|c|c|c|c|c|c|}
\hline $\begin{array}{l}\text { Pt. } \\
\text { no. }\end{array}$ & $\begin{array}{c}\text { Age } \\
\text { (years) }\end{array}$ & $\begin{array}{l}\text { Time of } \\
\text { castration } \\
\text { (months) }\end{array}$ & $\mathrm{CAB}$ & $\begin{array}{c}\text { AA } \\
\text { withdrawal }\end{array}$ & $\begin{array}{l}\text { Previous } \\
\text { treatment }\end{array}$ & $\begin{array}{l}\text { Pain } \\
(1-3)\end{array}$ & Other symptoms & $\begin{array}{l}\text { Bone } \\
\text { metastasis }\end{array}$ & $\begin{array}{l}\text { Other sites } \\
\text { of metastasis }\end{array}$ \\
\hline 1 & 50 & 45 & Yes & Yes & Atrasentan & 1 & Difficulty urinating & Yes & Lymph node \\
\hline 2 & 75 & 7 & Yes & Yes & None & 1 & & Yes & Liver \\
\hline 3 & 40 & 6 & Yes & No & None & 3 & $\begin{array}{l}\text { Partial ileus, recurrent infection, } \\
\text { fracture }\end{array}$ & Yes & $\begin{array}{l}\text { Lymph node, } \\
\text { liver, bladder }\end{array}$ \\
\hline 4 & 74 & 68 & Yes & Yes & Prednisone & 1 & & Yes & 0 \\
\hline 5 & 62 & 108 & Yes & Yes & Prednisone & 1 & & Yes & 0 \\
\hline 6 & 46 & 46 & Yes & Yes & None & 1 & & Yes & 0 \\
\hline 7 & 63 & 62 & Yes & Yes & $\begin{array}{l}\text { Predisone, } \\
\text { bisphosphonates, } \\
\text { Sendoxan }\end{array}$ & 2 & & No & Lymph node \\
\hline 8 & 65 & 84 & Yes & Yes & None & 1 & Edema & $\mathrm{NC}$ & 0 \\
\hline 9 & 62 & 36 & Yes & Yes & None & 1 & & Yes & 0 \\
\hline 10 & 58 & 56 & Yes & Yes & None & 1 & & Yes & 0 \\
\hline 11 & 59 & 104 & Yes & No & Prednisone & 1 & $\begin{array}{l}\text { Spinal cord, compression, } \\
\text { weakness in arms and legs }\end{array}$ & Yes & 0 \\
\hline 12 & 70 & 106 & Yes & No & None & 1 & Incontinence after TUR-P, lymphostasis & Yes & Lymph node \\
\hline 13 & 57 & 14 & Yes & No & None & 1 & Urine retention, supra-pubic catheter & Yes & Lymph node \\
\hline 14 & 63 & 35 & Yes & Yes & Prednisone & 1 & & $\mathrm{NC}$ & Lymph node \\
\hline 15 & 62 & 79 & Yes & Yes & None & 1 & & Yes & Lymph node \\
\hline 16 & 55 & 15 & Yes & No & None & 2 & Lymphostasis & Yes & Lymph node \\
\hline 17 & 59 & 17 & Yes & Yes & None & 1 & & Yes & Lymph node \\
\hline
\end{tabular}

TUR-P, transurethral resection of the prostate; NC, not confirmed; $\mathrm{CAB}$, combined androgen blockade; AA, anti-androgen.

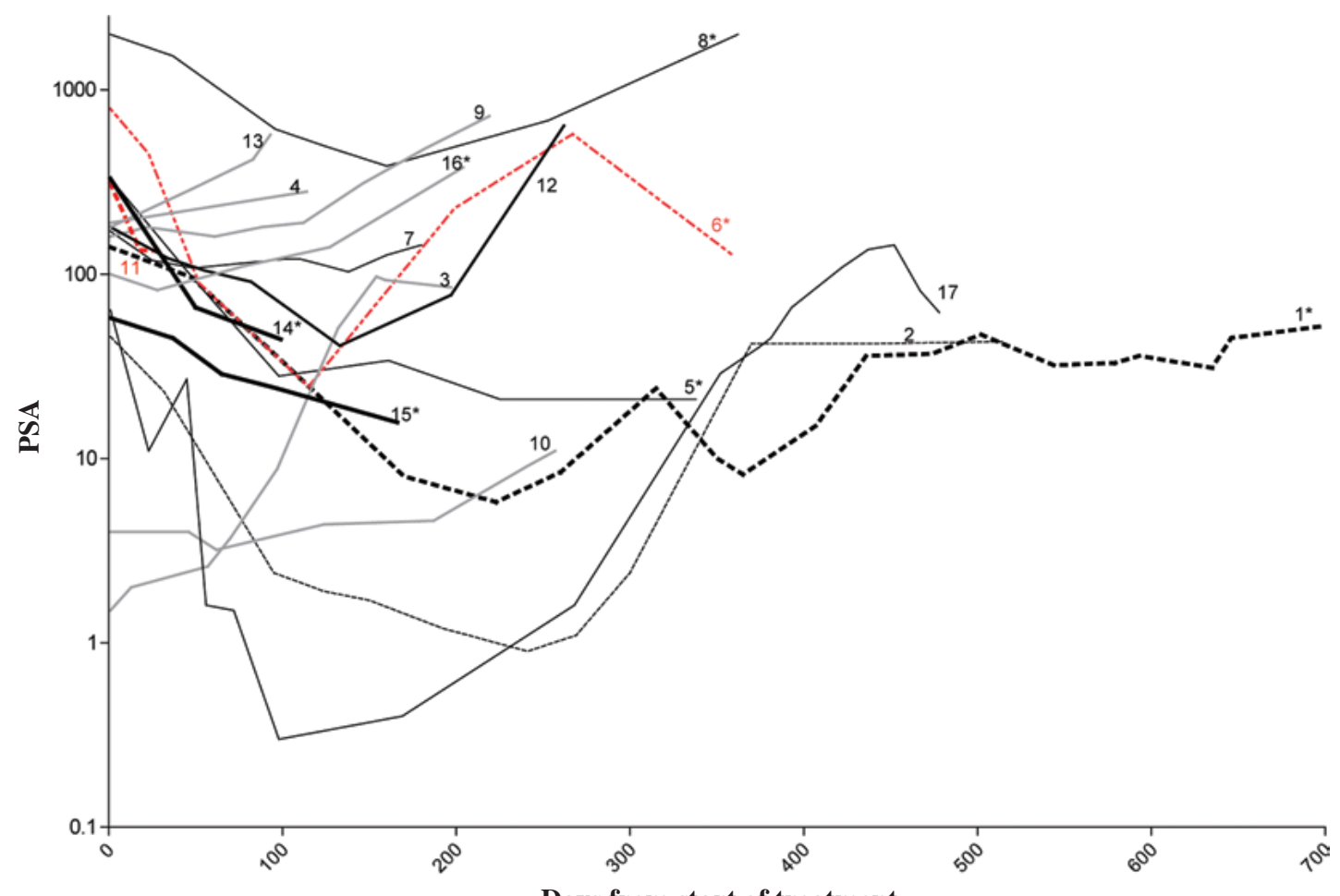

Days from start of treatment

Figure 1. Changes in prostate-specific antigen (PSA) after start of treatment. PSA levels of all 17 patients are shown. Numbers indicate patient no. as denoted in Table I. Patient no. 3, 4, 9, 10,13 and 16 did not respond to therapy with no reduction in PSA levels (grey lines). Patient no. 4 received treatment for only 4 days. "Patients treated with additional strontium $(\mathrm{Sr})-89$. 
Table II. Treatment planning and PSA levels before and after treatment.

\begin{tabular}{rcclcrrr}
\hline $\begin{array}{r}\text { Pt. } \\
\text { no. }\end{array}$ & $\begin{array}{c}\text { Age } \\
\text { (years) }\end{array}$ & $\begin{array}{c}\text { Courses of KEES } \\
\text { administered }\end{array}$ & Reasons for discontinued treatment & $\begin{array}{c}\text { Sr-89 } \\
\text { treatment }\end{array}$ & $\begin{array}{c}\text { PSA at start } \\
\text { of treatment }\end{array}$ & $\begin{array}{r}\text { PSA after } \\
\text { treatment }\end{array}$ & $\begin{array}{c}\text { Change in } \\
\text { PSA }\end{array}$ \\
\hline 1 & 50 & 3 courses & & Yes & 140.0 & 8.0 & $-94 \%$ \\
2 & 75 & $21 / 2$ courses & Thrombocytopenia & No & 23.0 & 1.2 & $-95 \%$ \\
3 & 40 & $<1 / 2$ course & Infections, compliance & No & 1.5 & 2.6 & - \\
4 & 74 & $1 / 2$ course & No response & No & 190.0 & 280.0 & $+47 \%$ \\
5 & 62 & 2 courses & & Yes & 330.0 & 28.0 & $-91 \%$ \\
6 & 46 & 2 courses & & Yes & 790.0 & 24.5 & $-97 \%$ \\
7 & 63 & 3 courses & & No & 171.0 & 144.0 & $-16 \%$ \\
8 & 65 & 3 courses & & Yes & 2400.0 & 386.0 & $-84 \%$ \\
9 & 62 & $11 / 2$ course & No response & No & 160.0 & 190.0 & $+19 \%$ \\
10 & 58 & 3 courses & & No & 4.0 & 4.6 & $+15 \%$ \\
11 & 59 & $1 / 2$ course & Death & No & 310.0 & 134.0 & $-57 \%$ \\
12 & 70 & 2 courses & & No & 180.0 & 41.0 & $-77 \%$ \\
13 & 57 & $1 / 2$ course & Thrombocytopenia, heart failure & No & 180.0 & 290.0 & $+61 \%$ \\
14 & 63 & 2 courses & & Yes & 330.0 & 44.4 & $-87 \%$ \\
15 & 62 & 3 courses & & Yes & 57.9 & 16.0 & $-72 \%$ \\
16 & 55 & 2 courses & & No & 100.0 & 110.0 & $+10 \%$ \\
17 & 59 & 2 courses & & Yes & 64.0 & 0.8 & $-99 \%$ \\
\hline
\end{tabular}

Normal serum PSA, $<3.0 \mu \mathrm{g} / \mathrm{l}$.

metastases received cyclophosphamide $50 \mathrm{mg} /$ daily while those with skeletal metastases and bone pain received zoledronic acid, $4 \mathrm{mg}$ monthly. In both groups treatment continued for 6 months.

Statistics. This study was a retrospective analysis, and descriptive statistics were used to analyze the data.

\section{Results}

PSA response. Of the 17 patients with CRPC treated with the KEES regime, 11 (65\%) patients demonstrated a median reduction in their serum PSA levels of $87 \%$ (range 26-99\%). Of these 11 patients, 7 (41\%) patients had a reduction in PSA level of $>80 \%, 3(18 \%)$ patients had a $57-77 \%$ reduction and one patient had a minor reduction of $26 \%$. Ten $(59 \%)$ patients responded with a decrease in PSA $>50 \%$.

All patients responding to treatment apart from one (pt. no. 11) received 2 or 3 courses of KEES over a period of 4-6 months. Although this patient had a 57\% reduction in PSA one month after therapy, his general condition deteriorated due to diarrhea and he died one month after the initiation of KEES therapy. No autopsy was performed, and the cause of death is unknown. Six patients (nos. 3, 4, 9, 10, 13 and 16) did not respond to treatment, since no reduction in PSA was observed. Details of the PSA level of each individual patient throughout the study are shown in Fig. 1.

Treatment was discontinued in 4 patients. Three patients (nos. 3, 4 and 13) were, in retrospect, in very poor condition at baseline and did not tolerate chemotherapy. One patient (no. 9) showed no response, and chemotherapy was discontinued because he forgot his androgen deprivation. Eight patients (nos. 1, 2, 5, 6, 8, 14, 15 and 17) were eligible for Sr-89, 5 patients after 2 courses and 3 patients after 3 courses of therapy. One of these patients (no. 2) could not be treated with Sr-89 due to thrombocytopenia (Table II).

Side effects and morbidity. Thrombocytopenia was the most common side effect. Four (24\%) patients (nos. 2, 4, 13 and 16) demonstrated thrombocytopenia. One patient (no. 2) needed repeated transfusions over a period of 2 months. Two additional patients (nos. 4 and 16) developed delayed thrombocytopenia. Anemia was the second most frequently observed side effect. Three (18\%) patients (nos. 2, 4 and 17) developed anemia that required erythrocyte transfusions. One patient developed acute cholestasis (bilirubin $214 \mu \mathrm{mol} / 1$, reference value 5-25) and elevated serum chreatinine (208 $\mu \mathrm{mol} / \mathrm{l}$, reference value 60-100) after his second KEES course. The signs and symptoms as well as blood tests returned to normal in 3 weeks. This same patient was retreated after one year with no observed side effects, and a favorable secondary response was achieved.

Two patients (nos. 14 and 17) experienced vascular complications in the form of thromboembolic events. One patient (no. 14) was initially on anti-coagulant treatment. In spite of this treatment, he developed a pulmonary embolus. Patient no. 17 developed a deep vein thrombosis. Other observed side effects were mild gastrointestinal symptoms (29\%), edema (12\%), diarrhea $(6 \%)$, skin rash $(6 \%)$ and elevation of liver enzymes $(6 \%)$. Alopecia showed a great degree of variability from mild to severe; only one patient experienced complete alopecia. All side effects/morbidities are presented in Table III.

One case of study fatality was reported. This patient's (no. 11) general condition deteriorated due to diarrhea, 
Table III. Side effects/morbidity observed among the patients treated with KEES

\begin{tabular}{|c|c|c|c|c|}
\hline $\begin{array}{l}\text { Pt. } \\
\text { no. }\end{array}$ & $\begin{array}{c}\text { Age } \\
\text { (years) }\end{array}$ & Mild & Moderate & Severe \\
\hline 1 & 50 & & Abdominal pain, weight loss $5 \mathrm{~kg}$ & \\
\hline 2 & 75 & & $\begin{array}{l}\text { Thrombocytopenia for }>1 \text { year, } \\
\text { anemia (need of transfusions) }\end{array}$ & $\begin{array}{l}\text { Thrombocytopenia (need of } \\
\text { transfusions for } 2 \text { months) }\end{array}$ \\
\hline 3 & 40 & & Repeated infections & \\
\hline 4 & 74 & Hypotension & Anemia, delayed thrombocytopenia & \\
\hline 5 & 62 & Nausea & & \\
\hline 6 & 46 & & & \\
\hline 7 & 63 & Fatigue & & \\
\hline 8 & 65 & Elevation of liver enzymes & Heart failure & \\
\hline 9 & 62 & Fatigue & & \\
\hline 10 & 58 & Skin rash, dyspepsia & & \\
\hline 11 & 59 & Fatigue, dyspepsia & Diarrhea & \\
\hline 12 & 70 & & & \\
\hline 13 & 57 & & Thrombocytopenia, heart failure & \\
\hline 14 & 63 & Thrombophlebitis & & Pulmonary embolism \\
\hline 15 & 62 & Dyspepsia & & \\
\hline 16 & 55 & & & $\begin{array}{l}\text { Delayed thrombocytopenia, } \\
\text { one transfusion }\end{array}$ \\
\hline 17 & 59 & $\begin{array}{l}50 \% \text { alopecia, vomiting, } \\
\text { abdominal pain, micturation problems }\end{array}$ & Anemia (need of transfusion) & $\begin{array}{l}\text { Deep vein thrombosis, } \\
\text { acute cholestasis }\end{array}$ \\
\hline
\end{tabular}

and he died one month after initiation of KEES therapy. Unfortunately no autopsy was performed, and the cause of death remains unknown.

\section{Discussion}

Treatment of patients with castration-resistant PC with a sequential metronomic chemo-hormonal therapy such as KEES appears to be beneficial with favorable PSA responses that compare with prior reports and with minor toxicity in contrast to what has been previously described for composite chemotherapy regimens.

Even though the use of docetaxel in PC has shown a lifeprolonging effect, it only modestly alters the natural history of castration resistant PC $(17,19)$. The timing and most effective strategy with which to treat the heterogeneous population of patients with CRPC, who are often elderly and with a great degree of comorbidity, remain largely undefined although several clinical trials are underway. As always, the goal is to define the optimum therapy with the most convenient route of administration and the least amount of side effects (7).

The KEES protocol was designed in an era when docetaxel was not available, and our aim was to create an entirely outpatient-based schedule with low toxicity using peroral administration as an alternative to an in-house patient setting. The KEES regimen described in this report was somewhat based upon an MD Andersson $(15,17,18)$ protocol. It was modified and converted to a fully peroral regimen. Therefore, doxorubicin and vinblastine were replaced with cyclophosphamide and etoposide both of which are also active in PC $(3,16,20-24)$. By combining secondary hormonal manipulation (ketoconazol, estramustine) with chemotherapy (etoposide, Sendoxan and estramustin) administered in a metronomic manner we sought to achieve a synergistic antitumor effect as previously described in experimental studies (23).

Here, we report PSA responses after 2-3 courses of KEES (4-6 months of therapy) where $59 \%$ of patients responded with a $>50 \%$ decline in PSA levels. This equals the response rates noted in docetaxel studies (TAX 327 and SWOG-9916) $(5,6)$. However, whether this reduction in PSA also corresponds to a prolonged progression-free and overall survival and increased quality of life remains to be shown, and a relevant study is currently underway. Several patients receiving consolidating therapy had long-lasting PSA responses (Fig. 1) (data not shown).

The toxicity observed in this study was less than previously described for composite chemo-hormonal or docetaxelcontaining regimens $(5,6,17,18)$. A major concern was the risk of thromboembolic complications in estramustine-containing protocols which in some trials has been as high as 30\% (25). We used a smaller dose of estramustine (140 mg twice daily) which is less than previous studies and may therefore explain the fewer incidents of thromboembolic events (18\%). This could, however, also be explained by the small number of patients. A major complication in docetaxel studies has been neutropenia which was not noted in this trial. In contrast, thrombocytopenia was the most frequently observed hematological side effect. Two of four patients required transfusions, but no events of bleeding were observed. Importantly, thrombocyte levels returned to normal levels for all four patients. Ketoconazol treatment is associated with an increased risk of liver toxicity, but in our study only one patient had elevated 
liver enzymes which is less than previously described $(26,27)$. To further minimize the risk of liver toxicity we used low-dose ketoconazole (200 mg twice daily) which has been shown to achieve equal responses as high-dose ketoconazol $(26,27)$. Taken together, with the exception of an increased risk of thrombocytopenia, the KEES protocol was well-tolerated.

It is not possible to analyze the contribution of the various therapeutic components to the responses observed in this small trial, yet it is likely that some drugs contributed to a greater extent than others. As mentioned earlier, all drugs were previously tested as single drugs or in combination for patients with CRPC. One could argue that some of the treatment effect could be contributed to prednisone which is probably true. However, single drug studies with prednisone in androgen-independent PC have shown PSA response rates of $16-24 \%$ which is far less than the rates noted in the present study (28).

In this small preliminary study, we showed that sequentially administered chemo-hormonal metronomic therapy appears to be less toxic than conventional scheduling with an MTD dose of docetaxel but with an equal effect on PSA levels. By yielding a lower accumulated dose, a more prolonged treatment was possible which is important considering the palliative situation of patients with CRPC. A treatment with low toxicity with the prospect of being used for an extended period of time with the added advantage of being easy to administer is the most favorable at the present time.

In conclusion, this small preliminary pilot study demonstrated that sequentially administered metronomic chemohormonal therapy is feasible for patients with castration-resistant PC.

\section{Acknowledgements}

This study was supported by grants from the Jubilee Clinic Cancer Research Foundation, Gothenburg, Swedish Cancer Society, Jubilee Fund, Stockholm, Foundation for Yngve Lands Memory, The Swedish Society of Medicine, The Health and Medical Care Committee of the region Västra Götaland.

\section{References}

1. Damber JE and Aus G: Prostate cancer. Lancet 371: 1710-1721, 2008.

2. Calabro F and Sternberg CN: Current indications for chemotherapy in prostate cancer patients. Eur Urol 51: 17-26, 2007.

3. Mike S, Harrison C, Coles B, Staffurth J, Wilt TJ and Mason MD: Chemotherapy for hormone-refractory prostate cancer. Cochrane Database Syst Rev CD005247, 2006.

4. Kantoff PW, Halabi S, Conaway M, et al: Hydrocortisone with or without mitoxantrone in men with hormone-refractory prostate cancer: results of the cancer and leukemia group B 9182 study. J Clin Oncol 17: 2506-2513, 1999.

5. Petrylak DP, Tangen CM, Hussain MH, et al: Docetaxel and estramustine compared with mitoxantrone and prednisone for advanced refractory prostate cancer. N Engl J Med 351: 1513-1520, 2004.

6. Tannock IF, de Wit R, Berry WR, et al: Docetaxel plus prednisone or mitoxantrone plus prednisone for advanced prostate cancer. N Engl J Med 351: 1502-1512, 2004.
7. Gignac GA, Morris MJ and Hussain M: Castration resistant, taxane-naive metastatic prostate cancer: current clinical approaches and future directions. J Urol 178: S30-S35, 2007.

8. Bradley DA and Hussain M: Promising novel cytotoxic agents and combinations in metastatic prostate cancer. Cancer J 14: 15-19, 2008.

9. Hanahan D, Bergers G and Bergsland E: Less is more, regularly: metronomic dosing of cytotoxic drugs can target tumor angiogenesis in mice. J Clin Invest 105: 1045-1047, 2000.

10. Kerbel RS and Kamen BA: The anti-angiogenic basis of metronomic chemotherapy. Nat Rev Cancer 4: 423-436, 2004.

11. Kerbel RS, Klement G, Pritchard KI and Kamen B: Continuous low-dose anti-angiogenic/metronomic chemotherapy: from the research laboratory into the oncology clinic. Ann Oncol 13: 12-15, 2002.

12. Kikuchi Y, Kita T, Takano M, Kudoh K and Yamamoto K: Treatment options in the management of ovarian cancer. Expert Opin Pharmacother 6: 743-754, 2005.

13. Stempak D, Seely D and Baruchel S: Metronomic dosing of chemotherapy: applications in pediatric oncology. Cancer Invest 24: 432-443, 2006

14. Tonini G, Schiavon G, Silletta M, Vincenzi B and Santini D: Antiangiogenic properties of metronomic chemotherapy in breast cancer. Fut Oncol 3: 183-190, 2007.

15. Ellerhorst JA, Tu SM, Amato RJ, et al: Phase II trial of alternating weekly chemohormonal therapy for patients with androgen-independent prostate cancer. Clin Cancer Res 3: 2371-2376, 1997.

16. Lord R, Nair S, Schache A, et al: Low dose metronomic oral cyclophosphamide for hormone-resistant prostate cancer: a phase II study. J Urol 177: 2136-2140, 2007.

17. Millikan R, Thall PF, Lee SJ, et al: Randomized, multicenter, phase II trial of two multicomponent regimens in androgenindependent prostate cancer. J Clin Oncol 21: 878-883, 2003.

18. Tu SM, Millikan RE, Mengistu B, et al: Bone-targeted therapy for advanced androgen-independent carcinoma of the prostate: a randomised phase II trial. Lancet 357: 336-341, 2001.

19. Logothetis CJ and Millikan R: Chemotherapy for advanced prostate cancer: 25 years later. J Clin Oncol 26: 2423-2424, 2008.

20. Berruti A, Fara E, Tucci M, et al: Oral estramustine plus oral etoposide in the treatment of hormone refractory prostate cancer patients: a phase II study with a 5-year follow-up. Urol Oncol 23: $1-7,2005$.

21. Bracarda S, Tonato M, Rosi $\mathrm{P}$, et al: Oral estramustine and cyclophosphamide in patients with metastatic hormone refractory prostate carcinoma: a phase II study. Cancer 88: 1438-1444, 2000.

22. Dimopoulos MA, Panopoulos C, Bamia C, et al: Oral estramustine and oral etoposide for hormone-refractory prostate cancer. Urology 50: 754-758, 1997.

23. Eigl BJC, Eggener SE, Baybik J, et al: Timing is everything: preclinical evidence supporting simultaneous rather than sequential chemohormonal therapy for prostate cancer. Clin Cancer Res 11: 4905-4911, 2005.

24. Glode LM, Barqawi A, Crighton F, Crawford ED and Kerbel R: Metronomic therapy with cyclophosphamide and dexamethasone for prostate carcinoma. Cancer 98: 1643-1648, 2003.

25. Fizazi K, Le Maitre A, Hudes G, et al: Addition of estramustine to chemotherapy and survival of patients with castration-refractory prostate cancer: a meta-analysis of individual patient data. Lancet Oncol 8: 994-1000, 2007.

26. Wilkinson S and Chodak G: An evaluation of intermediate-dose ketoconazole in hormone-refractory prostate cancer. Eur Urol 45: 581-585, 2004.

27. Harris KA, Weinberg V, Bok RA, Kakefuda M and Small EJ: Low dose ketoconazole with replacement doses of hydrocortisone in patients with progressive androgen independent prostate cancer. J Urol 168: 542-545, 2002.

28. Haines IE and Stanley RM: Perspective on 'Chemotherapy for advanced prostate cancer: 25 years later': Is it a mirage or an oasis? J Clin Oncol 26: 4049-4051, 2008. 